\title{
Acoustic Emission Characteristics and Energy Evolution of Red Sandstone Samples under Cyclic Loading and Unloading
}

\author{
Tianzuo Wang $\mathbb{D}^{1,2,3}$ Chunli Wang $\mathbb{D}^{1,2,3}$ Fei Xue $\mathbb{D}^{1,},{ }^{1,2,3}$ Linxiang Wang $\mathbb{D},{ }^{1,2,3}$ \\ Beyene Hana Teshome $\mathbb{D}^{1},{ }^{1,2,3}$ and Mengya Xue $\mathbb{i}{ }^{1,2,3}$ \\ ${ }^{1}$ School of Civil Engineering, Shaoxing University, Shaoxing 312000, China \\ ${ }^{2}$ Key Laboratory of Rock Mechanics and Geohazards of Zhejiang Province, Shaoxing 312000, China \\ ${ }^{3}$ Zhejiang Collaborative Innovation Center for Prevention and Control of Mountain Geologic Hazards, Shaoxing 312000, China
}

Correspondence should be addressed to Fei Xue; xuefei@usx.edu.cn

Received 2 September 2020; Revised 23 January 2021; Accepted 31 January 2021; Published 10 February 2021

Academic Editor: Paola Forte

Copyright $(92021$ Tianzuo Wang et al. This is an open access article distributed under the Creative Commons Attribution License, which permits unrestricted use, distribution, and reproduction in any medium, provided the original work is properly cited.

To explore the characteristics of rock deformation and failure under cyclic loading and unloading, the MTS815 rock mechanics test system and acoustic emission (AE) signal acquisition system were used to perform cyclic loading and unloading tests on red sandstone samples. The results showed that, compared with the uniaxial compression test, cyclic loading and unloading had a certain strengthening effect on the strength of the samples. The plastic deformation of the rock samples increased as the number of cycles increased. Based on AE signals, the cracking mode classification was analyzed on the basis of the average frequency and the rise angle of the waveforms. It was observed that the Felicity ratio gradually decreased with the increase in the stress level, which showed a cumulative damage effect. From the perspective of energy, the obvious increase of AE energy rate was mainly concentrated in the early and late stages of uniaxial compression, while the significant increase of dissipated energy rate occurred in the late stage of uniaxial compression. During the cyclic loading and unloading, most of the work done by external forces in the compaction stage and the elastic stage was converted into elastic strain energy, and dissipated energy began to gradually increase in the stage of stable fracture development. In addition, it was found that the damage evolution of the rock samples changed from slow to fast, and the dissipated energy ratio increased when failure was approaching.

\section{Introduction}

Many engineering practices have shown that the rock mass is often under an unstable state of repeated loading and unloading during engineering construction, such as excavation and reinforcement of high slopes, underground mining, and tunneling [1]. Existing studies have shown that the strength and deformation laws of rocks under cyclic loading are significantly different from those under monotonic loading $[2,3]$. In recent years, the acoustic emission (AE) technique has been widely used in solving rock and soil mechanics problems. It can be used to continuously monitor the development and destruction process of microcracks in rock samples in real time [4] and provide precursor information on rock instability and failure $[5,6]$. Thus, the AE technique was widely used in many fields such as materials engineering $[7,8]$, structural engineering $[9,10]$, mechanical equipment $[11,12]$, aerospace [13], and civil engineering [14, 15]. Kaiser [16] first discovered the phenomenon of AE in engineering materials and proposed the "Kaiser effect" in 1953. Then, Goodman [17] verified the Kaiser effect of rock $\mathrm{AE}$ through cyclic loading and unloading experiments in 1963. Thereafter, the study of AE focusing on rocks has never stopped. Rudajev et al. [18] revealed the $\mathrm{AE}$ characteristics of the rock failure process using a uniaxial compression test. Carpinteri et al. [19] compared the AE frequency amplitude statistics of the solid during the damage process with the defect size distributions of the disordered materials and found the key parameters that define the instability conditions of the monitored structure. Fu et al. [20] observed the Kaiser effect on Brazilian splitting and bending tests of marble and established 
the relationship between stress, strain, and AE. Meng et al. [21] conducted uniaxial cyclic loading and unloading compression at six different loading rates to investigate the energy accumulation, evolution, and dissipation characteristics and analyzed the stress-strain relationship and $\mathrm{AE}$ characteristics of the rock deformation and failure process. Liang et al. [22] found the effect of cyclic loading and unloading on the mechanical properties of the rock in the postpeak stage and proved that the deformation behavior of the rock was consistent with the AE parameters. Qin et al. [23] studied the mechanical properties and AE characteristics of sandstone under different loading paths and analyzed the macroscopic failure morphology through CT scanning and $3 \mathrm{D}$ image reconstruction. To explore the $\mathrm{AE}$ characteristics of soft rock, Zhao et al. [24] performed cyclic loading and unloading AE tests on sandstone and mudstone, respectively, and studied their deformation, failure characteristics, and the law of AE activities. Liu et al. [25] studied the AE characteristics of dry and saturated basalt columnar joints under uniaxial compression and analyzed tensile damage, the damage situation, AE parameters, and rock's damage AE precursor information. Wang et al. [26] conducted an in-depth study on the AE characteristics of granite under triaxial loading and discussed the types and development time of triaxial compression cracks. The destruction of rock under cyclic loading is a dynamic evolution process from crack development and compression to structural adjustment and instability. It is inevitable to be accompanied by the generation of $\mathrm{AE}$ signals. Therefore, to better understand the basic characteristics of rock damage and failure process, it is necessary to use the AE technique for real-time monitoring, which can contribute to a deep understanding of the damage and failure characteristics of rock samples during cyclic loading and unloading.

Meanwhile, the deformation and destruction of rocks are driven by energy evolution activities from the energy perspective. This perspective includes energy input, storage, dissipation, and release, which are essentially energy conversion $[27,28]$. It is an effective method to explore the rock failure problem under cyclic loading through the energy mechanism. Xie et al. [29, 30] explained the energy dissipation mechanism in the process of rock deformation and failure from the thermodynamics perspective and proposed a damage evolution equation based on energy dissipation analysis. You and Hua [31] and Chen et al. [32] found that the absorbed energy had a linear relationship with the confining pressure during rock failure. Carpinteri et al. [33] analyzed the experimental results of compression tests on cylindrical specimens of different types of rocks and concrete from the perspective of the balance between the energy stored, released, and absorbed during the complete loading process. Zhang et al. [34] investigated the effect of the confining pressure on the energy evolution characteristics and distribution relations under triaxial cyclic loading and unloading experiments. Gong et al. [35, 36] selected various rock samples for uniaxial compression, loading and unloading tests under different stress levels, and proposed a linear energy storage method and a rock burst tendency criterion.
In summary, a great number of efforts have been dedicated to the research on the mechanical properties, $\mathrm{AE}$ characteristics, and energy evolution laws of the loaded rock. However, the cyclic loading and unloading effects have a broad engineering background. It remains necessary to study the AE characteristics and energy evolution laws of rocks under cyclic loading and unloading, which is helpful to explore the corresponding relationship between the damage and destruction process of the loaded rock and the $\mathrm{AE}$ and energy. In this paper, cyclic loading and unloading tests of red sandstone samples were performed to mainly investigate the characteristics of $\mathrm{AE}$ and energy evolution in the entire process of rock deformation and failure.

\section{Experimental Procedures}

2.1. Sample Preparation. The red sandstone samples tested in the experiment were taken from Yueyang, Hunan Province, China. The sandstone samples are maroon with a fine grain structure and uniform texture. The main mineral components are quartz, feldspar, calcite, and iron. According to the international standards from the International Society for Rock Mechanics (ISRM), the rock samples were processed into cylindrical standard samples with a diameter of $50 \mathrm{~mm}$ and a height of $100 \mathrm{~mm}$. The parallelism of the upper and lower surfaces was controlled within $0.05 \mathrm{~mm}$, and the surface flatness was less than $0.02 \mathrm{~mm}$. The processed samples before the test were strictly screened to eliminate the samples with obvious damages and cracks on the surface. Moreover, the samples with abnormal wave speed and density were also eliminated through the ultrasonic test and density test. The red sandstone samples in the test were grouped and numbered, as listed in Table 1.

2.2. Experimental System. The MTS815.04 rock mechanics test system manufactured by the American MTS company was utilized in the test as the main loading equipment. The test system is composed of a loading system, a control system, and a monitoring system. It is a multifunctional electrohydraulic servo-controlled rigidity testing machine with excellent manual and program control functions, especially used for rock and concrete experiments. It has three independent closed-loop servo control functions for axial pressure, confining pressure, and pore water pressure. The $12 \mathrm{CH}$ sCI-2 AE test and analysis system produced by the Physical Acoustic Corporation was simultaneously applied to track the AE characteristics of samples during the loading process, as shown in Figure 1. A pair of axial and lateral extensometers was used for the deformation measurement, and six AE sensors were closely adhered to the rock sample to record AE signals, as shown in Figure 2.

Combining previous research and experiments, it is found that the sources of electromagnetic noises in the signal include flexing, twisting or transient impacting on coaxial cables, the poor contact of the AE probe, and the influence of the electromagnetic field generated by the external 
TABLE 1: Red sandstone sample groups and loading modes.

\begin{tabular}{lc}
\hline Samples & Experimental type \\
\hline R1 & Uniaxial compression \\
R2 & \\
R3 & \\
\hline R4 & Cyclic loading and unloading \\
R5 & \\
R6 & \\
\hline
\end{tabular}

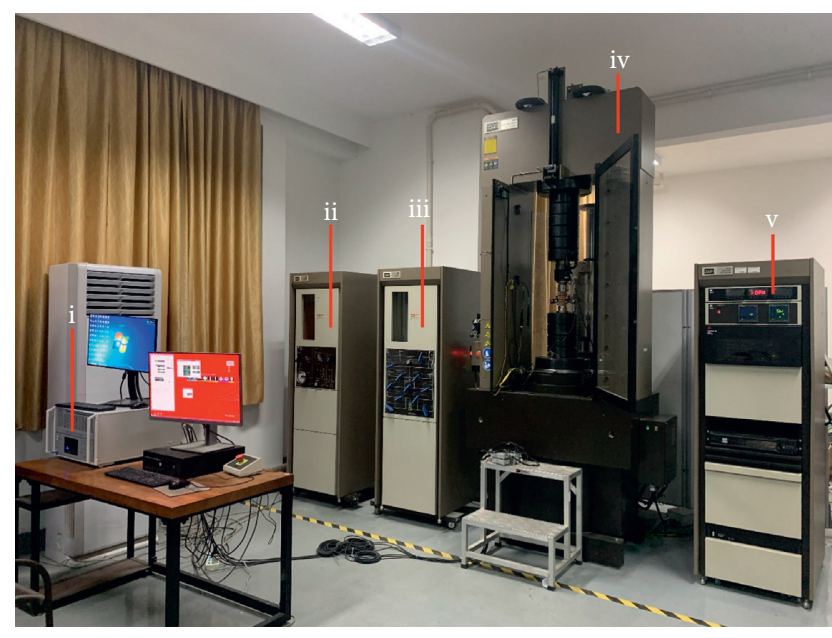

FIGURE 1: MTS815 rock mechanics test system. (i) AE workstation. (ii) Confining pressure intensifier. (iii) Pore pressure intensifier with permeability. (iv) Axial loading system. (v) Digital controller.

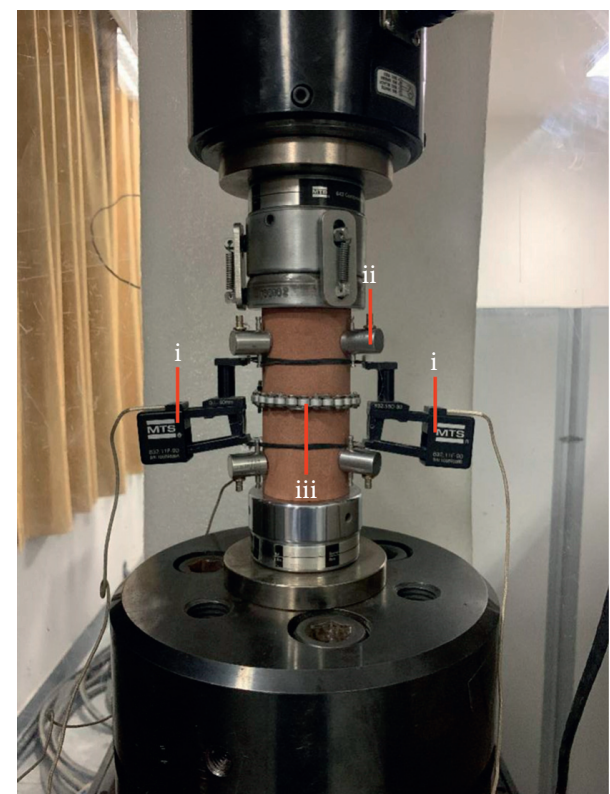

Figure 2: Rock sample. (i) Axial extensometer. (ii) AE sensor. (iii) Lateral extensometer.

environment. And it was also proved that most of the noise interference can be effectively filtered out by setting a threshold of $40 \mathrm{~dB}$. Therefore, $40 \mathrm{~dB}$ was set as the threshold in this experiment to avoid false signals generation.
2.3. Test Procedures. Uniaxial compression tests on samples R-1, R-2, and R-3 were first conducted to obtain an approximate uniaxial compressive strength, which can provide a reference for the formulation of the cyclic loading and unloading test program. Next, the cyclic loading and unloading test adopted axial stress control mode with a loading rate of $0.25 \mathrm{MPa} / \mathrm{s}$. The loading increment for each stage was set as $10 \mathrm{MPa}$. Each stage was first loaded to the preset value and then unloaded to $0 \mathrm{MPa}$. The above loading and unloading process was repeated until the red sandstone samples were fractured. The stress loading path was shown in Figure 3.

\section{Experimental Results and Analysis}

3.1. Strength and Deformation Characteristics Analysis. Figure 4 showed the stress-strain curves of rock samples in uniaxial compression tests. The complete stress-strain curves of rock samples under uniaxial cyclic loading and unloading were shown in Figure 5.

The average compressive strength of the rock samples under uniaxial compression was $74 \mathrm{MPa}$, while the average compressive strength of the rock samples under uniaxial cyclic loading and unloading was $78 \mathrm{MPa}$ with an increase of $5.4 \%$ compared to uniaxial compression. The rock sample used in the test was red sandstone in the natural state, and there were inevitably original cracks inside. Compared with the sample under uniaxial compression, there was only a microcrack compaction stage, while the microcracks inside the sample under cyclic loading were repeatedly pressed and closed. Thus, the compressive strength of the sample increased.

Figures 4 and 5 show that the envelope line of the uniaxial cyclic loading and unloading curves was similar to that of the uniaxial loading curves, which reflected the deformation memory of rock material. Some scholars obtained similar conclusions in the study of red sandstone [37]. In addition, the path of the unloading curve was not along the loading curve during uniaxial cyclic loading and unloading but lower than the loading curve. The loading curve and unloading curve did not coincide, forming a hysteresis loop, which was similar to a willow leaf with a wide middle part and sharp ends. When it was unloaded to $0 \mathrm{MPa}$, certain irreversible plastic deformation was generated. The elastic deformation recovered after each unloading, and the hysteresis loop continuously migrated forward. The area of the hysteresis loop was also gradually increased, indicating that the plastic deformation of the sample under cyclic loading and unloading would increase with the increase of the number of cycles.

\subsection{AE Characteristics of Rock Samples under Uniaxial} Compression. The AE generated by the loaded rock was mainly related to the generation, expansion, and connection of cracks, which can be used to reflect the internal damage of the rock. Figures 6 and 7 showed the curves of AE energy, AE count, and axial stress with respect to the loading time. AE energy was derived from the integral of the squared voltage 


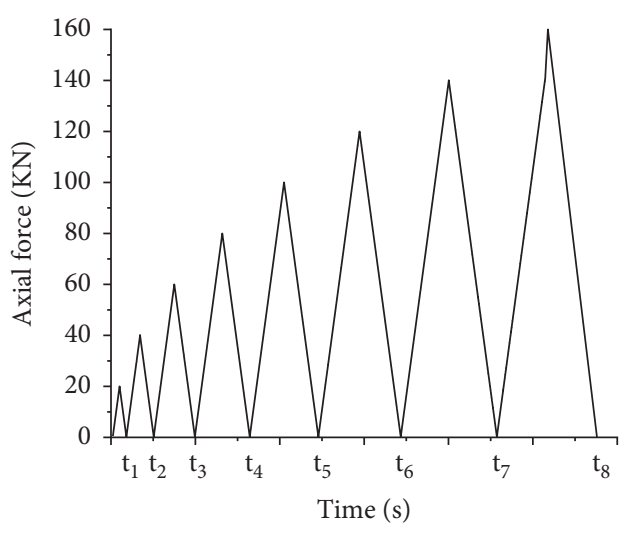

Figure 3: Stress loading path.

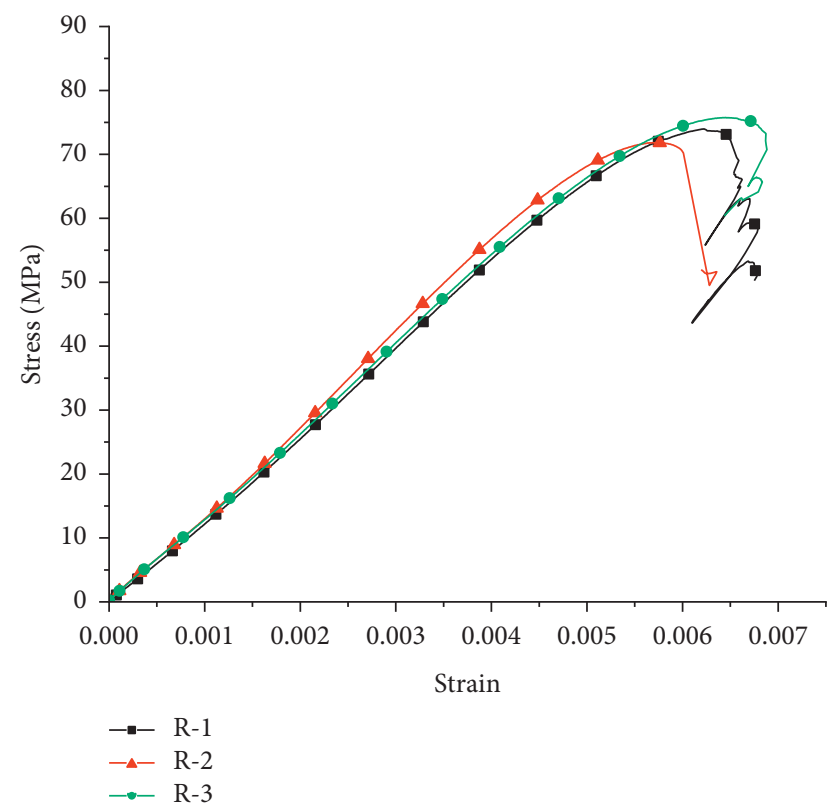

FIgURE 4: Stress-strain curves of rock samples in uniaxial compression tests.

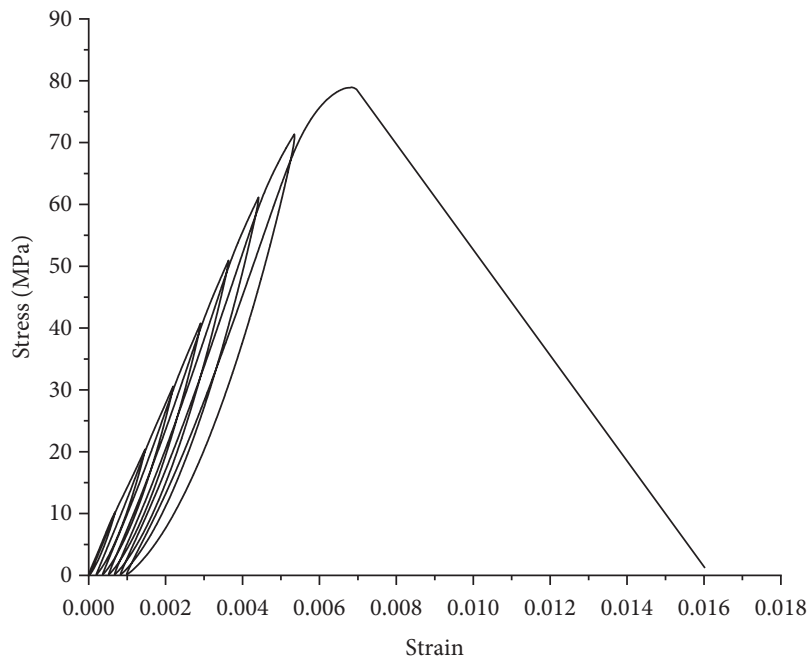

FIGURE 5: Complete stress-strain curves of rock samples under uniaxial cyclic loading and unloading.

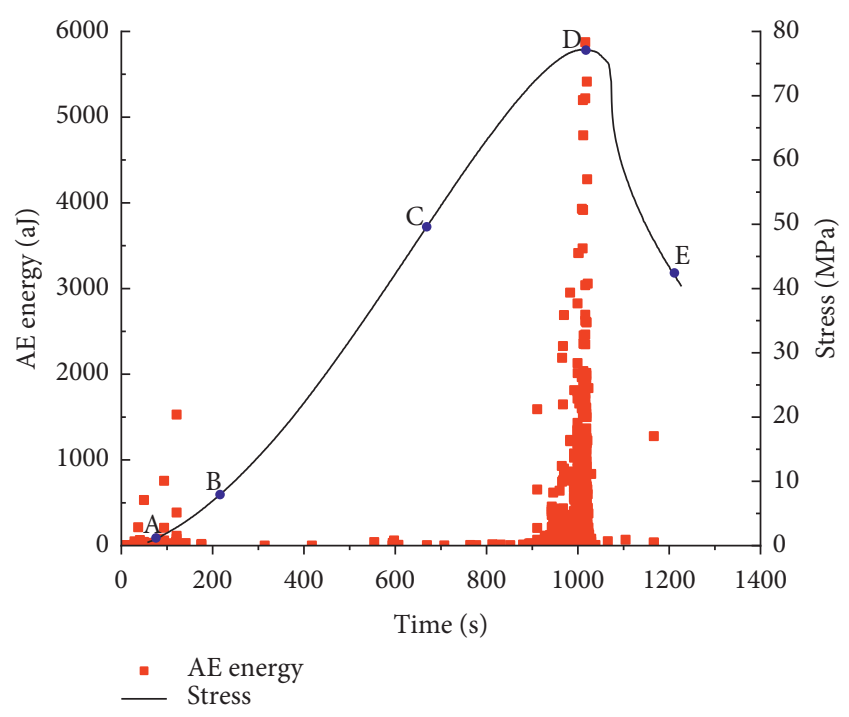

FIgURE 6: Relationships among AE energy, loading stress, and loading time of rock samples under the uniaxial compression tests.

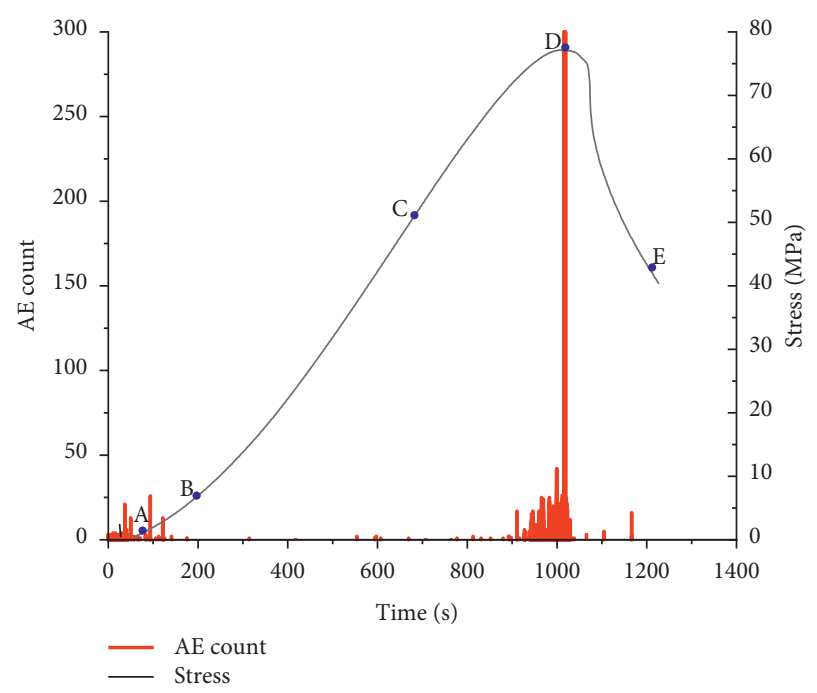

FIgURE 7: Relationships among AE count, loading stress, and loading time of rock samples under the uniaxial compression tests.

signal divided by the reference resistance $(10 \mathrm{k}$-ohm) over the duration of the $\mathrm{AE}$ waveform packet. It can be used as a characteristic value to characterize the true energy of $\mathrm{AE}$ impact. AE count was obtained by counting the number of $\mathrm{AE}$ signal excursions exceeding the AE threshold. The above parameters were directly exported through AEwin for PCI2 software.

Figures 6 and 7 showed that the stress-time curves of the rock samples can be roughly divided into four stages based on the distribution characteristics of the $\mathrm{AE}$ energy and count. Section $\mathrm{AB}$ was the pore and fissure compaction stage, during which the stress-time curve showed an upward concave shape. Only a few AE events occurred at this stage, and the AE energy was relatively low. The $\mathrm{AE}$ at this stage was mainly generated by the compression of the initial crack 
inside the rock sample. Section BC was the linear elastic stage of the rock sample, with the stress-time curve being approximately linear. Since this process was mainly elastic deformation and there was little microcrack propagation, $\mathrm{AE}$ count and energy remained basically calm. In section $\mathrm{CD}$, the rock sample entered the plastic stage of unsteady fracture development. Point $\mathrm{C}$ was the yield point. The AE began to gradually increase, and new cracks were continuously generated inside the rock sample. The development of microfracture has qualitatively changed, and the rupture continued to develop until the sample was completely fractured, resulting in the fact that $\mathrm{AE}$ count and energy drastically increased to the highest value. Section DE was the postfailure stage. The bearing capacity of the rock sample rapidly decreased. At this time, the microfracture was coalesced to form a macroscopic fracture surface. AE count still appeared after the rock sample fractured and reached a large value, but there was no specific law.

\subsection{AE Characteristics of Rock Samples under Cyclic Loading} and Unloading. The process of cyclic loading and unloading of rocks was accompanied by the compaction of primary fissures and the generation of new fissures. New cracks in the rock were continuously generated, developed, expanded, and penetrated with the increase in the number of cycles. Meanwhile, it was accompanied by the continuous generation of AE signals. Figures 8(a)-8(c) showed the curves of the $\mathrm{AE}$ energy and stress with time under the cyclic loading and unloading of rock samples R-4, R-5, and R-6. Figures 9(a)-9(c) showed the curves of the AE count and stress with time under the cyclic loading and unloading of rock samples R-4, R-5, and R-6.

In Figures 8 and 9, the stress level in the initial cycle was relatively low. The rock samples were in the compacting stage of primary fissures. New cracks were not produced, and the number of AE signals was small. The stress level further increased with the increase of the number of cycles, and new cracks began to appear in the rock samples. The $\mathrm{AE}$ energy was released as a result of the development and coalescence of cracks. The AE activity gradually entered the active period and reached the maximum at the last loading and unloading failure. In addition, the AE count was basically consistent with the change in $\mathrm{AE}$ energy. The $\mathrm{AE}$ count and AE energy significantly increased from the fourth cycle. The preset stress for the fourth cycle was $40 \mathrm{MPa}$, which was approximately $54 \%$ of the uniaxial compressive strength. Therefore, when the samples were loaded to $54 \%$ of the compressive strength, the damage continued to accumulate and eventually led to internal failure. Meanwhile, the rock samples entered the plastic deformation stage with the release of a considerable amount of AE energy. The internal cracks in the rock samples have developed and penetrated to form macroscopic cracks at the critical failure load. Unloading opened the fracture surface of the internal microstructure of the rock samples, which made the unloading process accompanied by more $\mathrm{AE}$ events.

The deformation and fracture process of rock included shear crack, tension crack, and tension-shear mixed crack.
Different crack modes were accompanied by AE signals with different characteristics. The average frequency (AF) and the rise angle of the waveforms (RA) were often used to analyze the crack mode of the rock samples [38, 39]. Figures $10(a)-10$ (c) showed the curves of RA value, AF value, and stress with respect to loading time under the cyclic loading and unloading of rock samples R-4, R-5, and R-6. Figures $11(\mathrm{a})-11(\mathrm{c})$ were the distribution diagram of the RA-AF relationship under the uniaxial cyclic loading and unloading compression of rock samples R-4, R-5, and R-6.

As shown in Figure 10, at the initial stage of loading and unloading, the internal cracks in the rock samples gradually closed, resulting in the phenomenon of high RA and low AF. At this time, shear stress played a major role in the rock samples. Subsequently, the phenomenon of high AF and low RA appeared during the second to the seventh cycle of loading. It can be inferred that tensile stress was the main stress during this period and a large number of microcracks began to appear. The microcracks were connected with each other, and the damage inside the rock samples gradually accumulated. At the same time, the RA value had an upward trend as the stress increased. When the critical failure occurred, both RA value and $\mathrm{AF}$ value increased to the maximum, and macroscopic cracks appeared under the combined action of tensile stress and shear stress. In addition, it can be seen from Figure 11 that the distribution of RA-AF had changed from dense to scattered. The rock samples had obvious characteristics of low RA and high AF, indicating that the tensile failure of the rock samples was more significant.

3.4. Change of AE Felicity Ratio in Cyclic Loading and Unloading. The AE phenomenon reflected the development and expansion degree of microcracks in rocks; that is, it was the manifestation of its internal damage. Figures 8 and 9 showed that there was a significant increase in $\mathrm{AE}$ even when the stress level was lower than the previous maximum stress level. This result reflected the Felicity effect of the AE phenomenon of the rock under uniaxial cyclic loading and unloading, which showed the irreversibility of the $\mathrm{AE}$ $[40,41]$. To better describe the irreversibility of rock samples, the Felicity effect was introduced. Felicity ratio is a measure of rock damage and defined as

$$
R_{F}(i)=\frac{\sigma_{i}}{\sigma_{i-1(\max )}},
$$

where $R_{F}(i)$ is the Felicity ratio of the $i$ th loading-unloading cycle, $\sigma_{i}$ is the stress level when AE rings begin to significantly increase in the $i$ th loading-unloading cycle, and $\sigma_{i-1(\max )}$ is the maximum stress level in the $(i-1)$ th loading-unloading cycle.

In the study of the Felicity effect ratio, there was no uniform standard for the significantly increased AE. According to the guiding principle recommended by CARP, $\mathrm{AE}$ count above 20 was studied as the basic value [42]. Figure 12 showed the change in Felicity ratio with the number of cycles. 

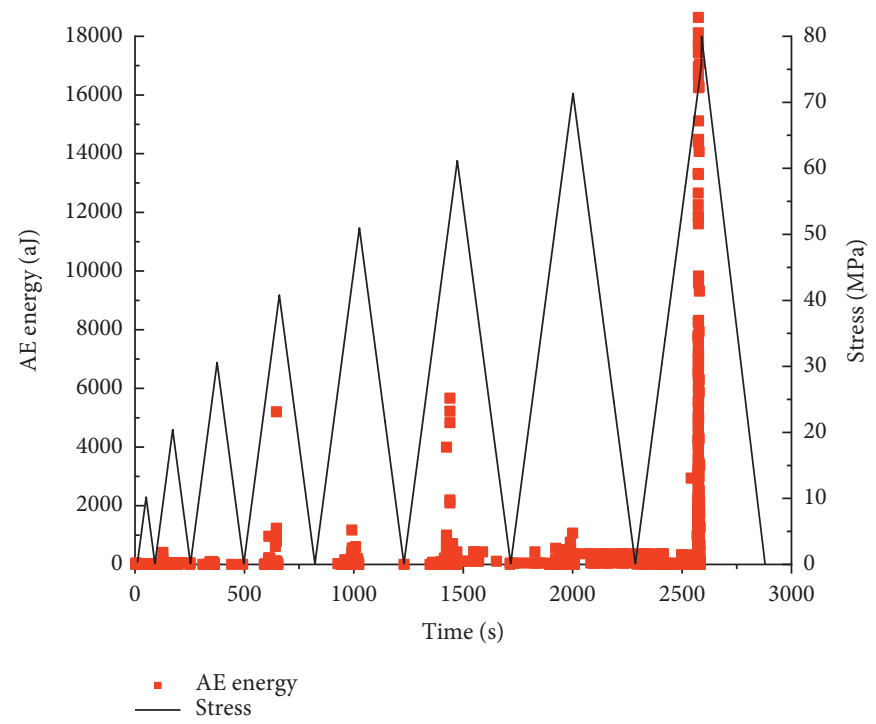

(a)

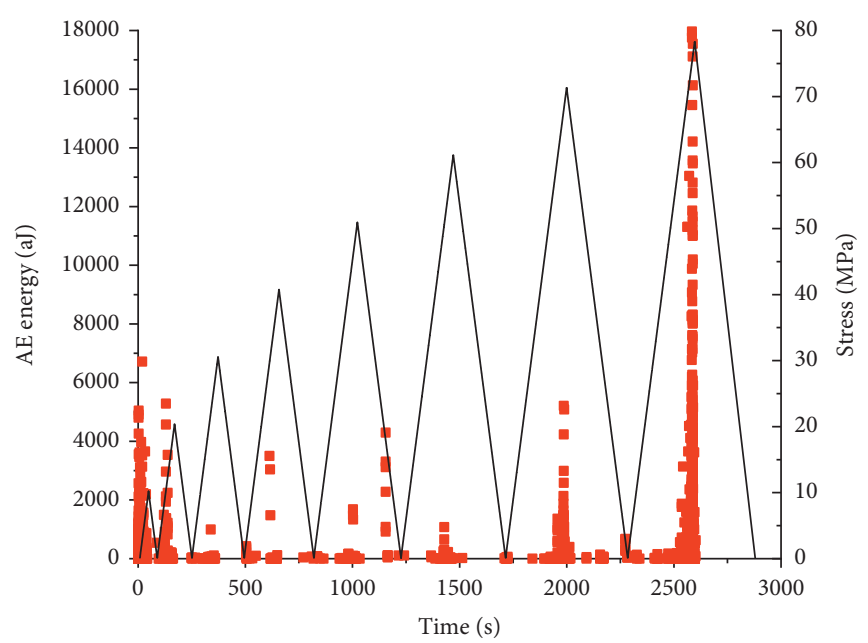

- AE energy

Stress

(b)

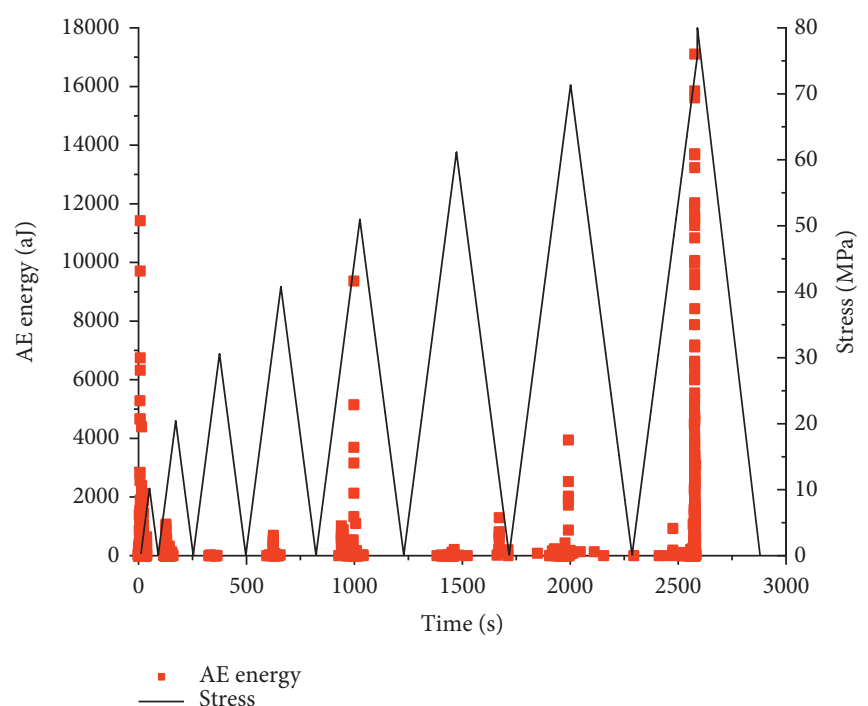

(c)

FIgURE 8: Relationships among AE energy, loading stress, and monitoring time of rock samples under the uniaxial cyclic loading and unloading compression: (a) graph of rock sample R-4, (b) graph of rock sample R-5, and (c) graph of rock sample R-6. 


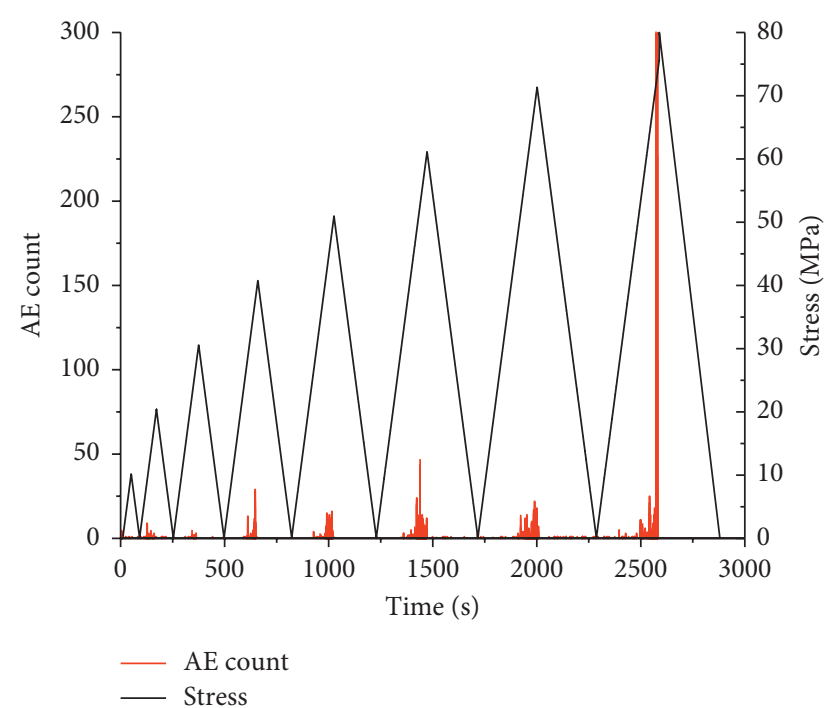

(a)

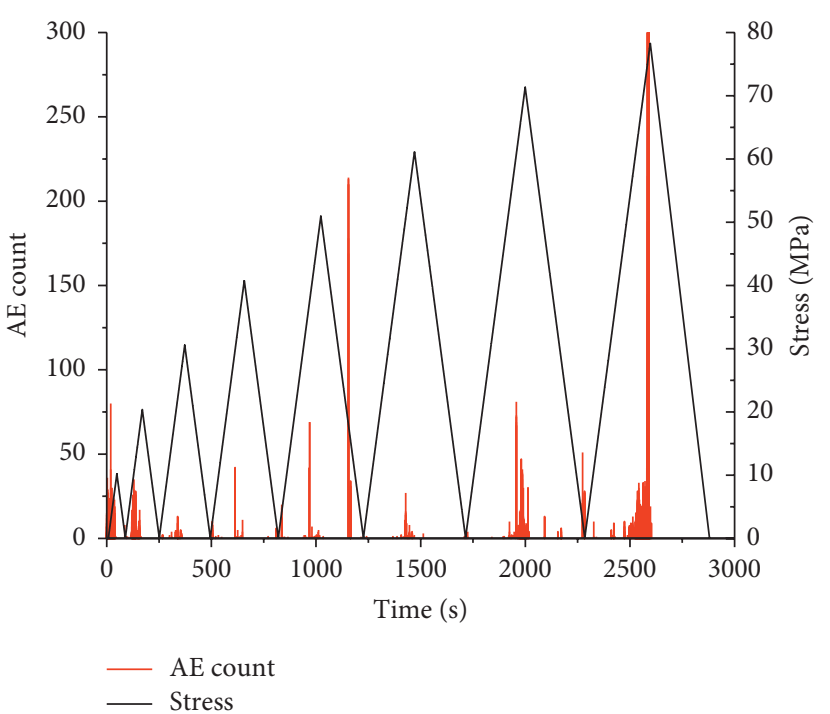

(b)

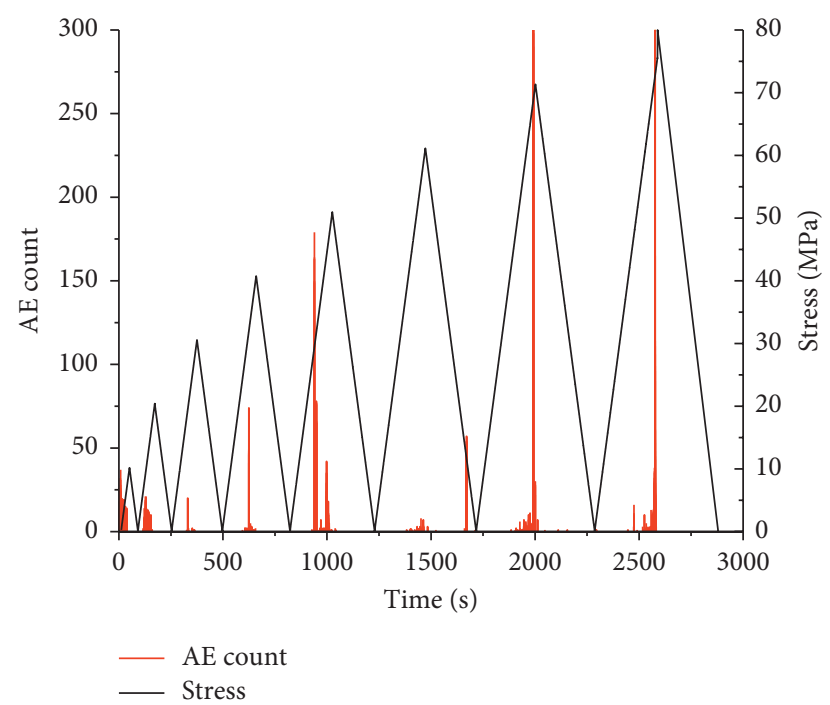

(c)

FIGURE 9: Relationships among AE count, loading stress, and monitoring time of rock samples under the uniaxial cyclic loading and unloading compression: (a) graph of rock sample R-4, (b) graph of rock sample R-5, and (c) graph of rock sample R-6.

Figure 12 showed that the Felicity ratio decreased with the increase of the number of cycles, indicating that the internal damage degree of the rock samples had been increasing. As a result, the degree of irreversibility of $\mathrm{AE}$ of rock samples continued increasing, which reflected the cumulative effect of rock damage. Felicity ratio was greater than 1 at the initial stage of low stress. It showed that the rock samples were in the compaction stage. The pores and microcracks in the rock samples were gradually closed to generate $\mathrm{AE}$ signals, and the damage degree was relatively low at this time. Felicity ratio gradually decreased with the increase of the stress level. For example, for R-4, the ratio decreased from the initial value of 1.27 to 1.05 after the second cycle. R-4 entered the elastic deformation stage after the compaction stage, with a low stress level. The $\mathrm{AE}$ characteristic of the rock samples showed the Kaiser effect, and the damage degree was extremely low. The rock samples entered the plastic deformation stage when the stress level further increased. The cracks inside the rock samples continued to develop and penetrate and the internal damage continued to accumulate. Felicity ratio significantly decreased from 1.05 to 0.55 after the third cycle. The average Felicity ratio of the rock samples was 0.54 in the seventh cycle. The damage degree was severe due to the stable development of cracks in the rock samples. The Felicity ratio maintained a decreasing trend after the seventh cycle, but the decreasing trend became slow. At this moment, the rock samples were in the failure stage. The internal cracks rapidly expanded and the corresponding damage degree was maximal. 


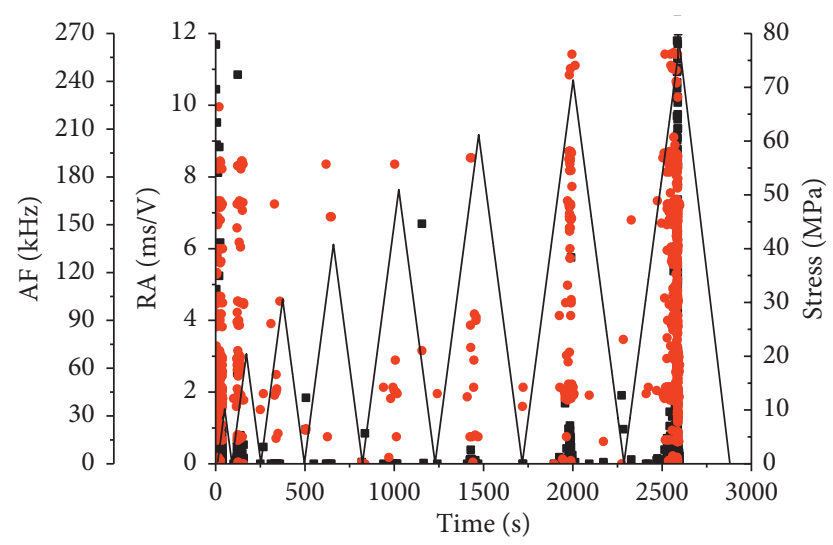

- RA

- $\mathrm{AF}$
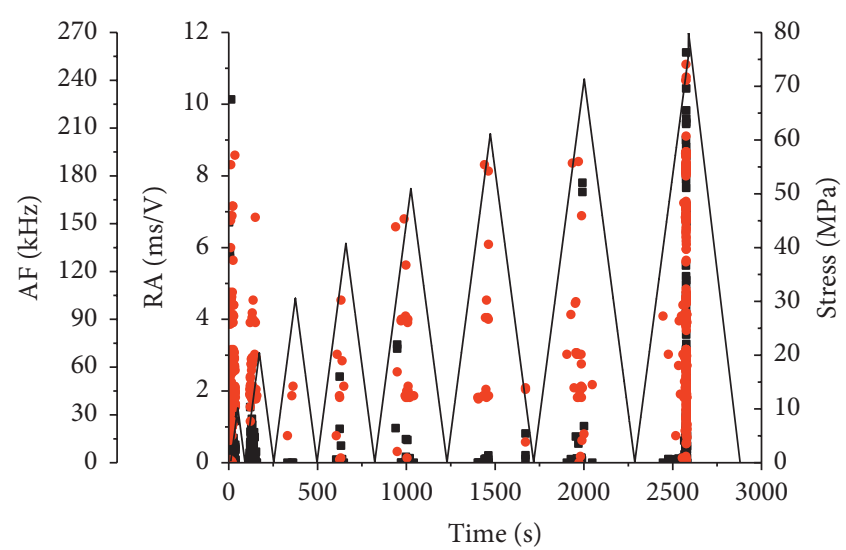

- RA

- $\mathrm{AF}$

(a)

(b)

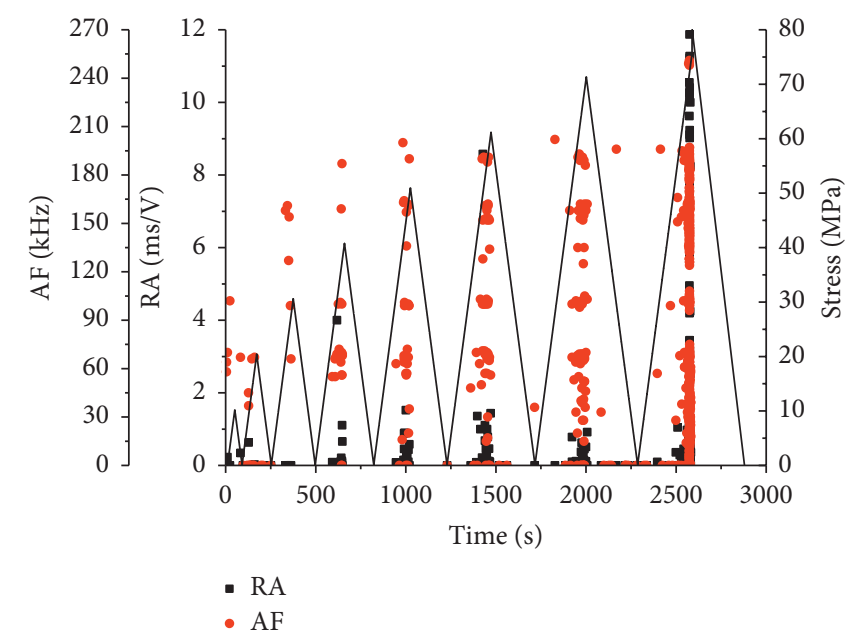

(c)

FIGURE 10: Relationships between RA value, AF value, loading stress, and loading time of rock samples under the uniaxial cyclic loading and unloading compression: (a) graph of rock sample R-4, (b) graph of rock sample R-5, and (c) graph of rock sample R-6.

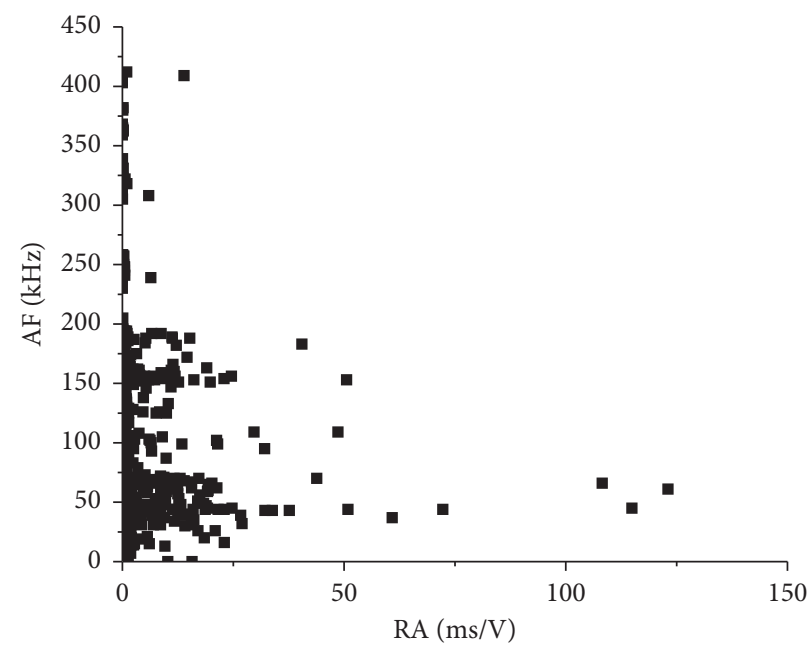

(a)

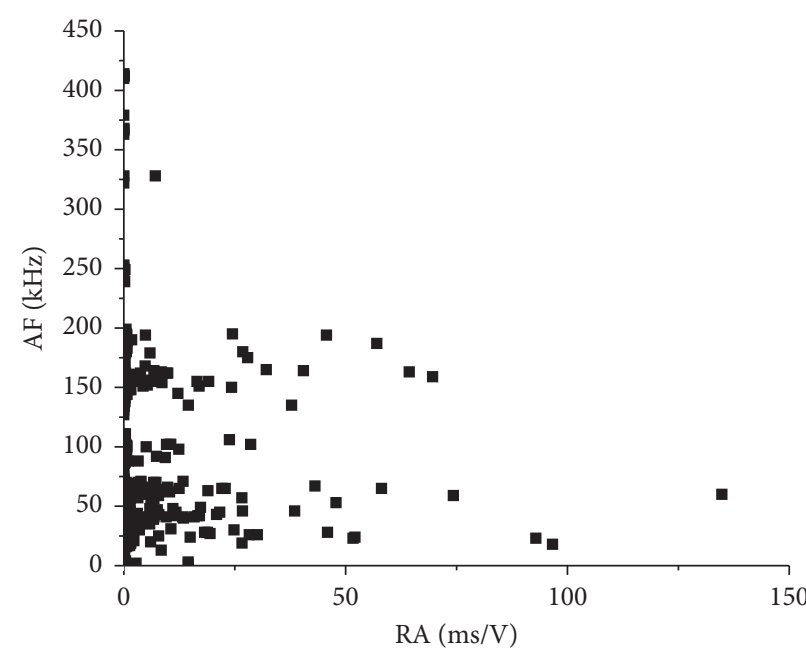

(b)

Figure 11: Continued. 


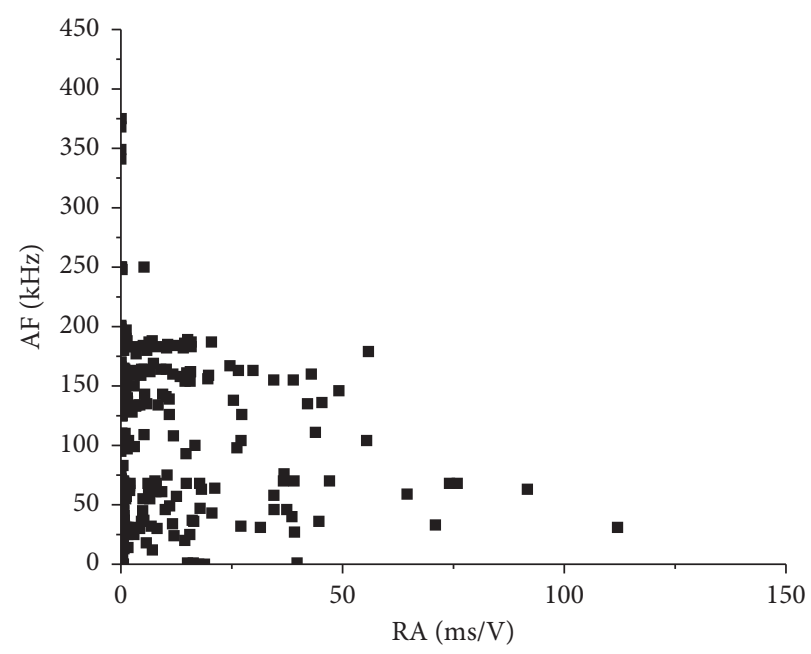

(c)

FIGURE 11: Distribution diagram of RA-AF relationship under the uniaxial cyclic loading and unloading compression: (a) graph of rock sample R-4, (b) graph of rock sample R-5, and (c) graph of rock sample R-6.

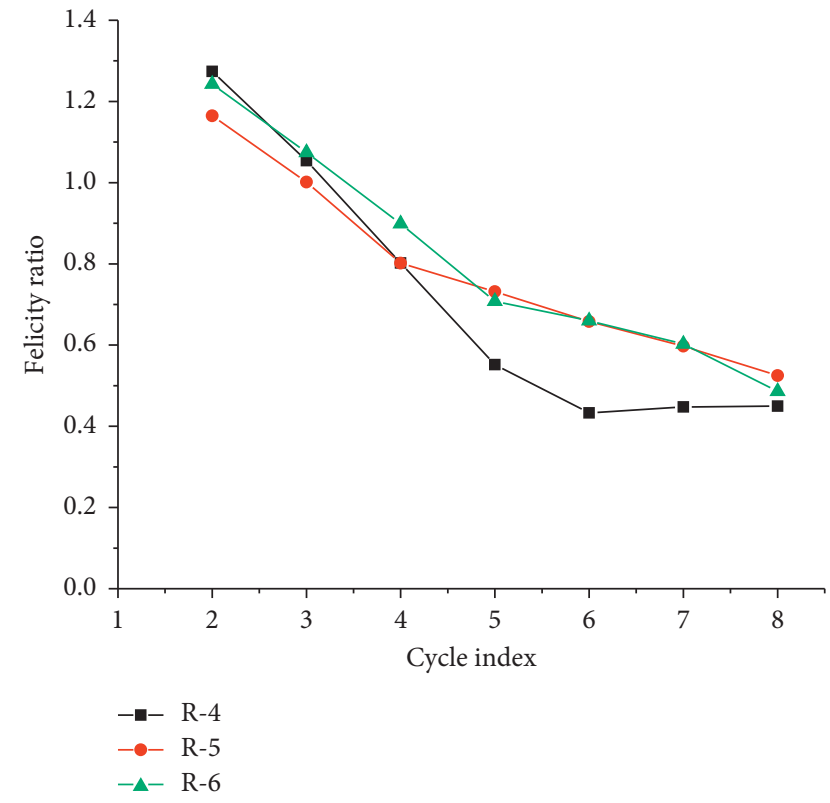

FIGURE 12: Variation of Felicity ratio with increasing loading stress.

\section{Analysis of Energy Evolution Characteristics}

4.1. Calculation of Energy under Uniaxial Compression. AE technique can be used to obtain information on the form of energy release and the development of crack modes. Recent studies [43-45] have shown that there is a certain relationship between crack propagation and emitted energy. In this experimental study, it was found that the red sandstone also had a snap-back phenomenon after the peak stress under the uniaxial compression, and a lot of AE activities would occur during this instability period. The phenomenon was due to the fact that the dissipation through rock material damage was not enough to dissipate all the elastic strain energy stored inside, which caused the unconsumed part of the energy to be emitted suddenly, resulting in the dynamic vibration and propagation of elastic waves. The schematic diagram of the snap-back phenomenon was shown in Figure 13. This emitted energy can be detected by the AE sensors.

According to the calculation method of dissipated energy rate in the article [43], the calculation steps were listed as follows:

(i) It was necessary to find the elastic limit in the uniaxial load-displacement curve.

(ii) According to the elastic limit, the corresponding time point in the load-time diagram was found, and it was subdivided from this time point.

(iii) Each subdivision time point corresponded to a load, and the corresponding load value returned to the load-displacement curve.

(iv) Dissipated energy rate was defined by line segments parallel to elastic branches, as shown in the shaded part.

The schematic diagram of calculating the dissipated energy rate was shown in Figure 14. The curve of dissipated energy rate and $\mathrm{AE}$ energy rate with respect to loading time was depicted in Figure 15.

As illustrated in Figure 15, the dissipated energy rate and AE energy rate had different change trends. At the beginning of loading, the natural fractures of the rock samples were gradually compacted, and the weak elastic waves continued to be released as the fractures closed. Thus, there was an obvious increase in the AE energy rate at this time. Thereafter, it entered the stage of elastic deformation. The AE entered a quiet period, while a lower dissipated energy rate appeared. When the rock samples entered the plastic stage, new cracks were constantly produced inside the rock samples. More high-energy AE signals can be collected 


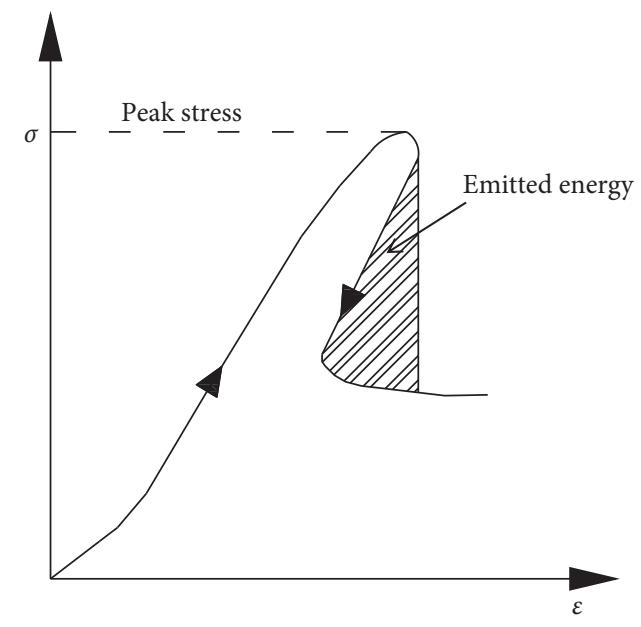

FIgURE 13: Schematic diagram of the snap-back phenomenon.

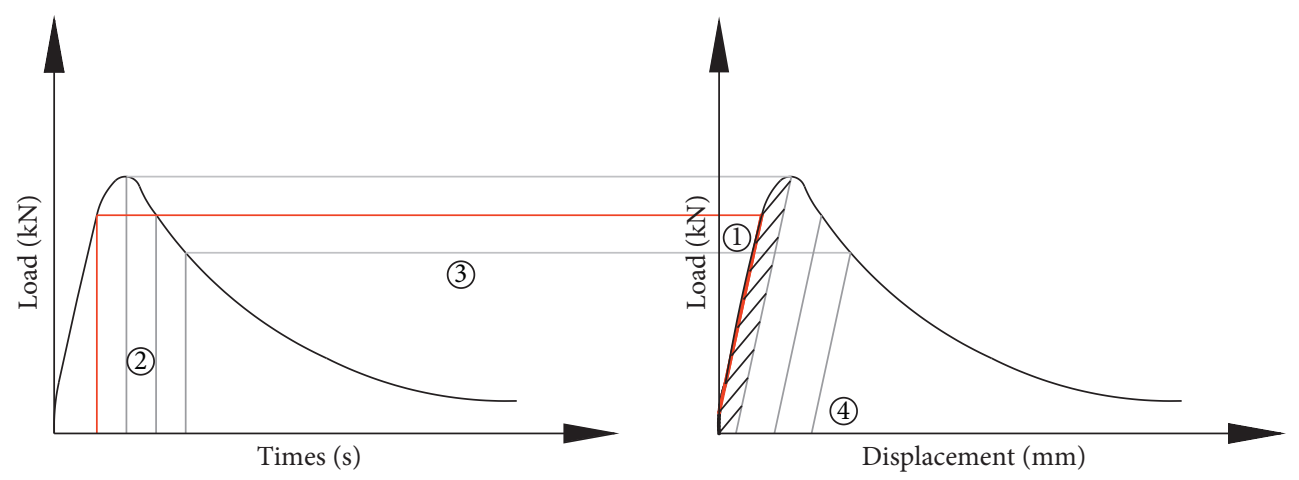

FIGURE 14: Schematic diagram of calculating dissipation energy rate [43].

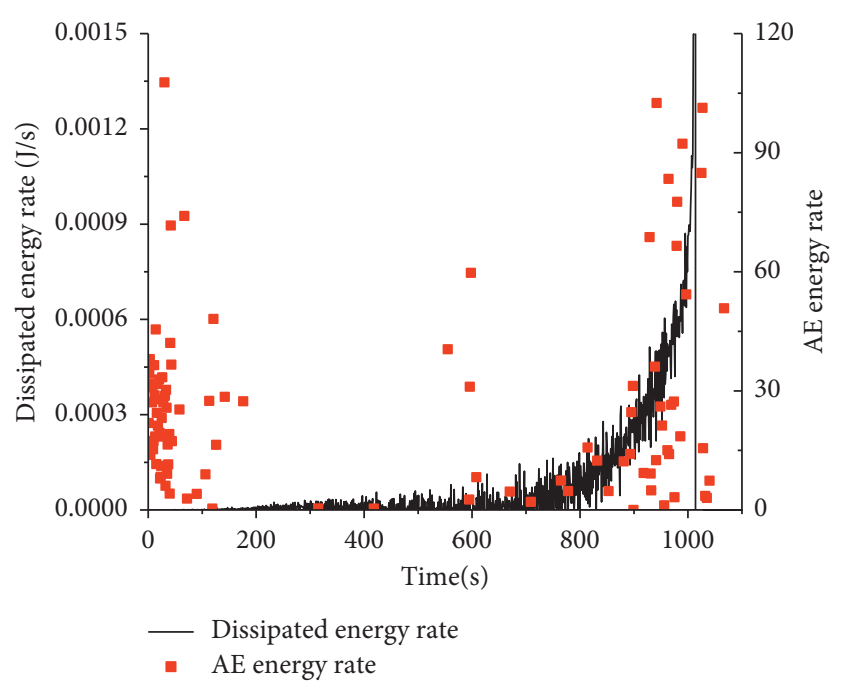

FIGURE 15: Relationships among dissipated energy rate, AE energy rate, and loading time of rock samples under uniaxial compression.

gradually, indicating that the rock samples have begun to deteriorate at this stage. It can be seen that the dissipated energy rate and AE energy rate increased sharply in the late loading stage, indicating that the internal fractures of the rock samples were rapidly expanding, with the rock samples being seriously damaged. When the dissipated energy rate and the AE energy rate reached the maximum value, the cracks in the rock samples rapidly developed and penetrated, and the rock samples were greatly damaged.

4.2. Calculation of Energy under Cyclic Loading and Unloading. In the process of test loading, the work done by the external load on the rock during the entire cyclic loading and unloading process is the total work. According to the law of conservation of energy, the rock and the outside environment are constantly exchanging energy during the entire loading and unloading process, which converts the work done by the external load into elastic strain energy and dissipation energy. As shown in Figure 16, the area sandwiched between the lower part of loading curve OA and the $x$-axis is the total work done by the external load, that is, input energy density $E$. The area between the bottom of the unloading curve $\mathrm{AB}$ and the $x$ axis is elastic energy density $E_{e}$ released by the rock sample. The total work done by the external load minus the elastic deformation energy of the rock sample is the dissipated energy density $E_{d}$, which is the area between the loading and unloading curves, as shown in the shaded part of OAB. The energy density $E$ can be defined as 


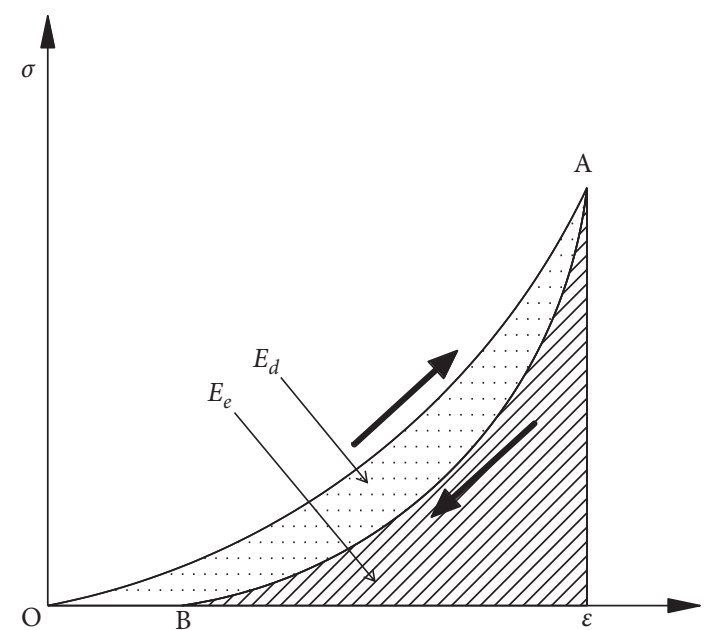

FIgURE 16: Diagram of an energy density calculation.

$$
E=E_{e}+E_{d}
$$

where $E$ is the input energy density, $\mathrm{MJ} / \mathrm{mm}^{3} ; E_{e}$ is the elastic energy density, $\mathrm{MJ} / \mathrm{mm}^{3} ; E_{d}$ is the dissipated energy density, $\mathrm{MJ} / \mathrm{mm}^{3}$. Elastic energy density $E_{e}$ and dissipated energy density $E_{d}$ released by the rock sample in each cycle can be calculated by calculating the area.

4.3. Energy Evolution Law of Rock Samples. According to the above energy calculation method and test curve, the elastic energy density and dissipated energy density of the three rock samples were calculated and shown in Tables 2-4. The proportion of elastic energy density $E_{e}$ to input energy density $E$ is defined as elastic energy ratio $R_{e}$. The ratio of dissipated energy density $E_{d}$ to input energy density $E$ is defined as dissipated energy ratio $R_{d}$; equations (3) and (4) are as follows:

$$
\begin{aligned}
& R_{e}=\frac{E_{e}}{E}, \\
& R_{d}=\frac{E_{d}}{E} .
\end{aligned}
$$

Figures $17(\mathrm{a})-17(\mathrm{c})$ are drawn from the data in Tables 2-4, which were the development curves of the elastic energy density and dissipated energy density at different stages of rock samples R-4, R-5, and R-6.

In Figures $17(\mathrm{a})-17(\mathrm{c})$, the three samples had very similar change trends of elastic energy density. The curves were relatively gentle and showed a nonlinear growth with a relatively slow growth rate in the initial compaction stage, as the elastic energy density stored in the rock samples was gradually released during unloading. The rock samples entered the linear elastic stage after the compaction stage, during which the elastic energy density was released again during unloading. It showed a linear growth with a faster growth rate. The elastic energy density reached the maximum and began to release when the stress was maximal. Thus, most of the work done by the external force was
TABLE 2: Energy calculation results of R-4.

\begin{tabular}{lcccc}
\hline$\sigma(\mathrm{MPa})$ & $E_{e}\left(\mathrm{MJ} / \mathrm{mm}^{3}\right)$ & $E_{d}\left(\mathrm{MJ} / \mathrm{mm}^{3}\right)$ & $R_{e}$ & $R_{d}$ \\
\hline 10 & 0.0023 & 0.0013 & 0.6404 & 0.3596 \\
20 & 0.0103 & 0.0052 & 0.6639 & 0.3361 \\
30 & 0.0222 & 0.0092 & 0.7073 & 0.2927 \\
40 & 0.0383 & 0.0149 & 0.7203 & 0.2797 \\
50 & 0.0579 & 0.0223 & 0.7223 & 0.2777 \\
60 & 0.0841 & 0.0329 & 0.7190 & 0.2810 \\
70 & 0.1180 & 0.0470 & 0.7154 & 0.2846 \\
\hline
\end{tabular}

TABLE 3: Energy calculation results of R-5.

\begin{tabular}{lcccc}
\hline$\sigma(\mathrm{MPa})$ & $E_{e}\left(\mathrm{MJ} / \mathrm{mm}^{3}\right)$ & $E_{d}\left(\mathrm{MJ} / \mathrm{mm}^{3}\right)$ & $R_{e}$ & $R_{d}$ \\
\hline 10 & 0.0024 & 0.0015 & 0.6088 & 0.3912 \\
20 & 0.0106 & 0.0057 & 0.6509 & 0.3491 \\
30 & 0.0222 & 0.0106 & 0.6768 & 0.3232 \\
40 & 0.0380 & 0.0164 & 0.6983 & 0.3017 \\
50 & 0.0584 & 0.0226 & 0.7210 & 0.2790 \\
60 & 0.0838 & 0.0340 & 0.7114 & 0.2886 \\
70 & 0.1164 & 0.0506 & 0.6970 & 0.3030 \\
\hline
\end{tabular}

TABLE 4: Energy calculation results of R-6.

\begin{tabular}{lcccc}
\hline$\sigma(\mathrm{MPa})$ & $E_{e}\left(\mathrm{MJ} / \mathrm{mm}^{3}\right)$ & $E_{d}\left(\mathrm{MJ} / \mathrm{mm}^{3}\right)$ & $R_{e}$ & $R_{d}$ \\
\hline 10 & 0.0023 & 0.0017 & 0.5704 & 0.4296 \\
20 & 0.0103 & 0.0060 & 0.6319 & 0.3681 \\
30 & 0.0219 & 0.0110 & 0.6653 & 0.3347 \\
40 & 0.0381 & 0.0163 & 0.7007 & 0.2993 \\
50 & 0.0582 & 0.0236 & 0.7120 & 0.2880 \\
60 & 0.0839 & 0.0329 & 0.7184 & 0.2816 \\
70 & 0.1161 & 0.0519 & 0.6911 & 0.3089 \\
\hline
\end{tabular}

converted into elastic energy and stored in the rock samples during the compaction and elastic stages. In addition, the dissipated energy density of the three rock samples first slowly increased with the increase of the loading stress. The dissipated energy density began to gradually increase when the microcracks in the rock samples gradually generated, developed, steadily expanded, and entered the stage of stable fracture development. The dissipated energy density of the rock samples increased in a positive correlation with the increase of the loading stress, indicating that a greater loading stress corresponded to a greater dissipation energy. The internal cracks in the rock samples had penetrated and formed macroscopic cracks when the rock samples were close to failure. A lot of energy was consumed in the process and the dissipation energy density significantly increased. The elastic energy stored in the rock samples at the initial stage was released in a large amount and converted into dissipated energy. When the rock samples were finally broken, a crisp sound was made.

4.4. Energy Distribution Law of Rock Samples. Energy dissipation will cause damage to the rock, and energy release is the inherent reason for the sudden destruction of the entire 


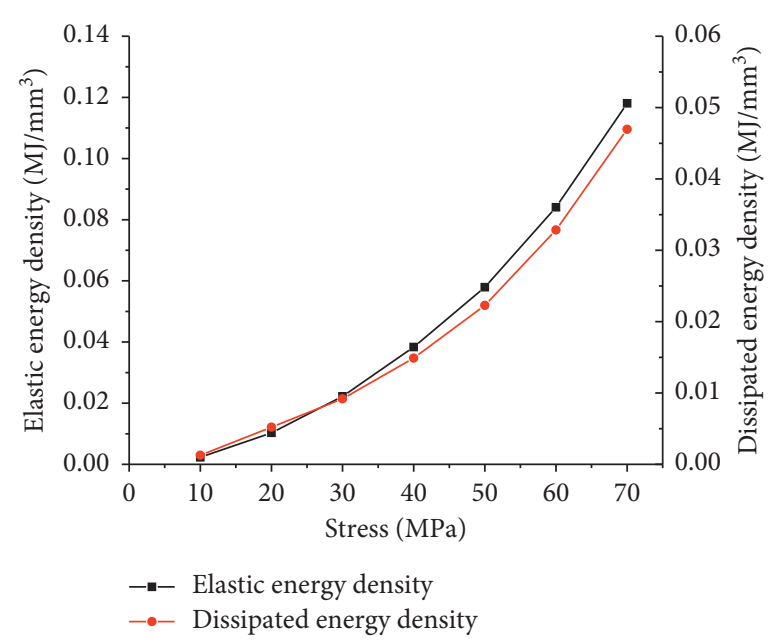

(a)

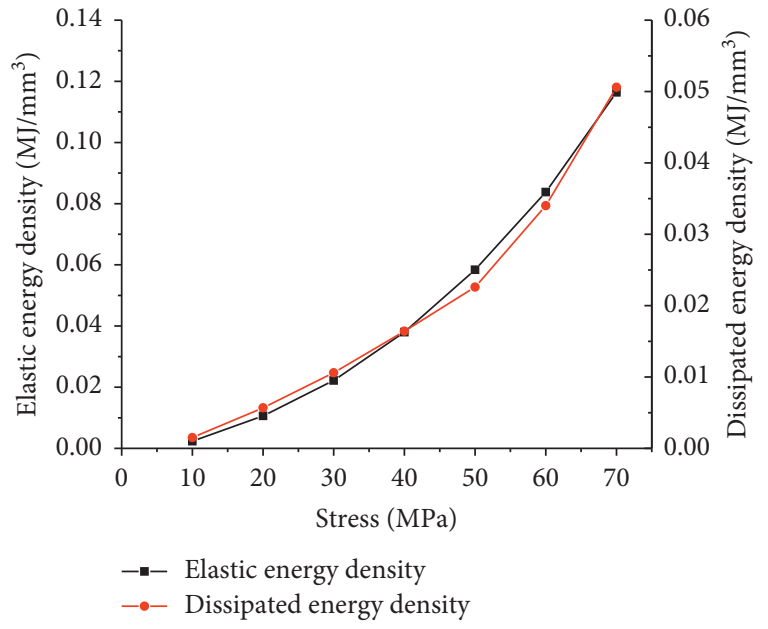

(b)

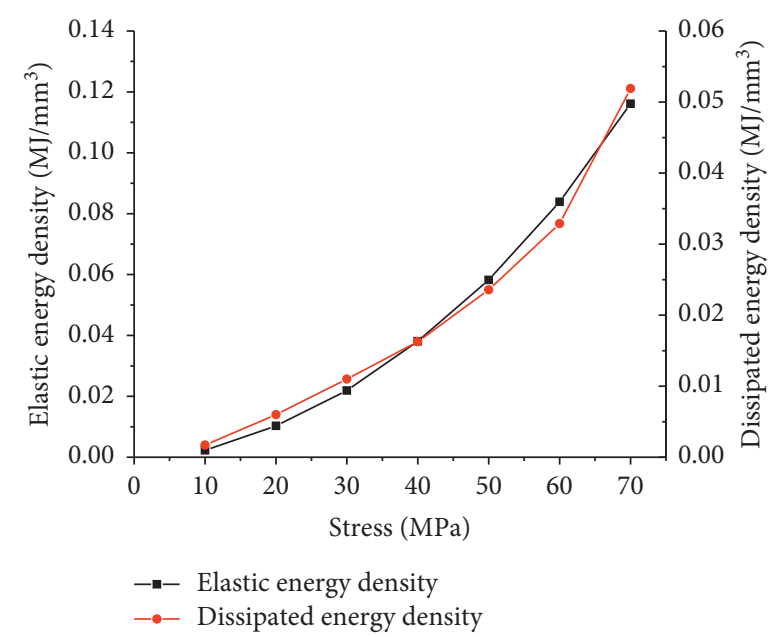

(c)

FIGURE 17: Development curve of the elastic energy density and dissipated energy density at different loading stages: (a) graph of rock sample R-4, (b) graph of rock sample R-5, and (c) graph of rock sample R-6.

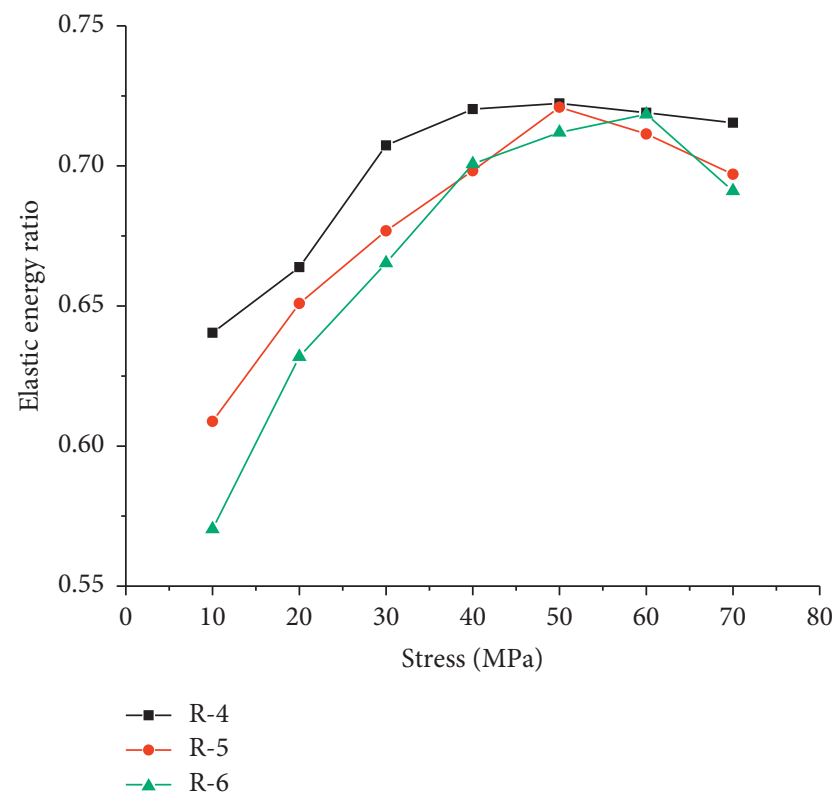

FIGURE 18: Relation curves between elastic energy ratio and axial stress.

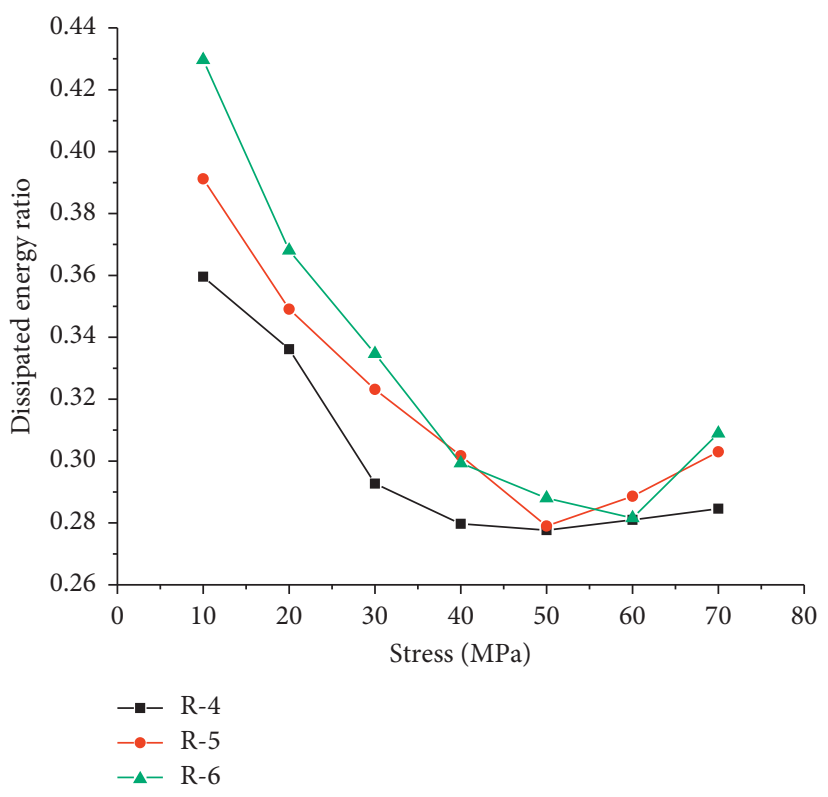

Figure 19: Relation curves between dissipated energy ratio and axial stress. 
rock $[46,47]$. To better explore the changes in energy during the deformation and failure process of red sandstone samples under cyclic loading and unloading, the changes in elastic energy ratio and dissipated energy ratio were analyzed. Figures 18 and 19 were obtained from the data in Tables 2-4, which showed the relationships between elastic energy ratio, dissipated energy ratio, and axial stress.

The elastic energy ratio nonlinearly changed with the stress during the cyclic loading and unloading process of the red sandstone samples. In the initial stage of loading, the elastic energy ratio sharply increased with the increase in stress. The crack entered the stage of stable propagation when the axial stress approached approximately $40 \%$ of the peak strength, and the growth rate of the elastic energy ratio gradually decreased. Then the crack entered the stage of unstable crack propagation when the load reached the peak strength level of $65 \sim 80 \%$, and the growth rate of elastic energy ratio further decreased. The elastic energy ratio slightly decreased near the failure of the samples. However, the dissipated energy ratio had been decreasing before the failure, and it had a slight increase as it approached failure.

Most of the work done by external forces had been converted into elastic energy at the initial stage of loading, but the difference between the two was very small due to the microcrack closure inside the samples, and the friction and the slip among particles consumed a lot of energy. It entered the linear elastic deformation stage and stable development stage of microfracture as the axial stress increased, and most of the pores in the rock samples have been compacted. Meanwhile, new microcrack initiation resulted in the dissipation of a small amount of energy. The microcracks inside the rock samples expanded, connected, and formed macrocracks as the failure approaches, which must consume more dissipated energy so that the dissipated energy ratio increased.

4.5. Analysis of Damage Evolution Based on Dissipated Energy. The internal microcracks of the loaded rock were first compacted, then reextended, and penetrated until it was fractured. The whole process was always accompanied by energy release and dissipation and always followed the law of conservation of energy. The energy dissipated during the loading process was mainly used to form damage and caused the loss of rock strength. This paper defined the damage variable based on the irreversible dissipated energy during the deformation of the rock material [46], aiming to study the characteristics of damage evolution during the deformation and failure of red sandstone under cyclic loading and unloading conditions. Its definition is listed as equations (5) and (6). The change curve of damage variable with loading time is shown in Figure 20.

$$
\begin{aligned}
D_{(i)} & =\frac{U_{d(i)}}{U_{d}}, \\
D & =\sum_{1}^{i} D_{(i)}=\sum_{1}^{i} \frac{U_{d(i)}}{U_{d}},
\end{aligned}
$$

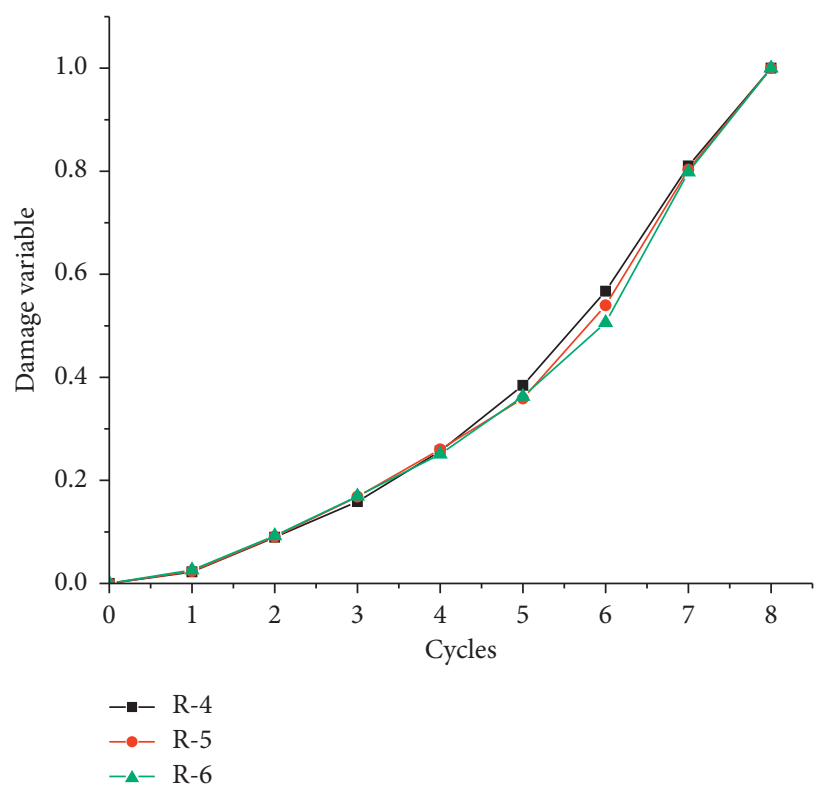

FIGURE 20: Variation of damage variable with the number of cycles.

where $D_{(i)}$ is a single-cycle damage variable; $U_{d(i)}$ is the dissipated energy of single-cycle loading and unloading; $U_{d}$ is the total dissipated energy of destruction under cyclic loading and unloading; $D$ is the cumulative damage variable; $i$ is the number of cycles.

From the above figure, it was found that the damage evolution of the rock samples changed from slow to fast. Due to the slow development of internal cracks in the rock samples at the beginning of loading, the damage variable basically increased at a uniform low rate. When loaded to the fifth cycle, the damage accounted for $37 \%$ of the total damage, and the damage of the rock samples started to grow faster. As the cracks inside the rock samples developed and connected, the growth rate of the damage variable was further accelerated, indicating that the degree of rock damage became more serious. When the load reached the seventh cycle, the internal cracks were connected to each other, and the degree of rock damage was close to failure. Subsequently, the damage variable reached its maximum value, and the rock samples were completely destabilized and destroyed.

\section{Conclusions}

In this paper, the cyclic loading and unloading tests were performed to comprehensively understand the deformation and strength characteristics of red sandstone under cyclic loading and unloading from the perspective of $\mathrm{AE}$ and energy theory. The following conclusions are obtained:

(1) Compared with the compaction stage where there were only microcracks in the uniaxial compression test, the microcracks inside the samples were repeatedly closed under the action of cyclic loading and unloading, which had a certain strengthening effect on the compressive strength of the rock samples. 
(2) When the number of loading cycles increased, the hysteresis loop continuously migrated forward during the cyclic loading and unloading process of the rock samples. It gradually moved in the direction of increasing stress, and its area was increased, indicating that the plastic deformation of rock samples increased with the increase of the number of cycles.

(3) The AE count and AE energy significantly increased when the load reached $54 \%$ of the compressive strength of the rock samples. The damage continued to accumulate, which caused internal damage. Through the analysis of changes in RA and AF, it was found that tensile failure in the rock samples was more significant under cyclic loading and unloading. The Felicity ratio continuously decreased with the increase of the stress level. The degree of internal damage of the rock sample was gradually accumulating, which made the irreversible degree of $\mathrm{AE}$ of rock samples continue to increase.

(4) The dissipated energy rate and the AE energy rate under uniaxial compression had different changes. In the cyclic loading and unloading test, most of the work done by external forces was converted into elastic energy and stored inside the rock samples in the compaction and elastic stages of rock loading. The dissipation energy slowly increased with the stress at the beginning, and it significantly increased when the rock samples were near the failure. The elastic energy ratio slightly decreased when the samples were close to failure, while the dissipated energy ratio changed in the opposite manner. Based on the damage analysis of the dissipated energy, it was found that the damage evolution of rock samples changed from slow to fast during cyclic loading and unloading.

\section{Data Availability}

The data used to support the findings of this study are included within the article.

\section{Conflicts of Interest}

The authors declare that they have no conflicts of interest.

\section{Acknowledgments}

The authors would like to acknowledge the financial support for this study provided by the National Natural Science Foundation of China (Grant no. 41831290) and the Natural Science Foundation of Zhejiang Province (Grant no. LQ20E080006).

\section{References}

[1] D. Li, Z. Sun, T. Xie, X. Li, and P. G. Ranjith, "Energy evolution characteristics of hard rock during triaxial failure with different loading and unloading paths," Engineering Geology, vol. 228, pp. 270-281, 2017.
[2] K. Fuenkajorn and D. Phueakphum, "Effects of cyclic loading on mechanical properties of Maha Sarakham salt," Engineering Geology, vol. 112, no. 1-4, pp. 43-52, 2010.

[3] N. Erarslan and D. J. Williams, "Investigating the effect of cyclic loading on the indirect tensile strength of rocks," Rock Mechanics and Rock Engineering, vol. 45, no. 3, pp. 327-340, 2012.

[4] S. Kramadibrata, G. M. Simangunsong, K. Matsui, and H. Shimada, "Role of acoustic emission for solving rock engineering problems in Indonesian underground mining," Rock Mechanics and Rock Engineering, vol. 44, no. 3, pp. 281-289, 2011.

[5] V. Vishal, P. G. Ranjith, and T. N. Singh, "An experimental investigation on behaviour of coal under fluid saturation, using acoustic emission," Journal of Natural Gas Science and Engineering, vol. 22, pp. 428-436, 2015.

[6] E. A. Novikov, R. O. Oshkin, V. L. Shkuratnik, S. A. Epshtein, and N. N. Dobryakova, "Application of thermally stimulated acoustic emission method to assess the thermal resistance and related properties of coals," International Journal of Mining Science and Technology, vol. 28, no. 2, pp. 243-249, 2018.

[7] W. Q. Han, Y. Luo, A. J. Gu, and F. G. Yuan, "Damage modes recognition and Hilbert-Huang transform analyses of CFRP laminates utilizing acoustic emission technique," Applied Composite Materials, vol. 23, no. 2, pp. 155-178, 2016.

[8] P. V. Vara and R. J. Nageswara, "A review on acoustic emission characterization of failure modes of carbon fiber reinforced composites," Advanced Materials Research, vol. 1148, pp. 43-47, 2018.

[9] M. Rabiei and M. Modarres, "Quantitative methods for structural health management using in situ acoustic emission monitoring," International Journal of Fatigue, vol. 49, pp. 81-89, 2013.

[10] T. Fu, Y. Liu, Q. Li, and J. Leng, "Fiber optic acoustic emission sensor and its applications in the structural health monitoring of CFRP materials," Optics and Lasers in Engineering, vol. 47, no. 10, pp. 1056-1062, 2009.

[11] T. Toutountzakis and D. Mba, "Observations of acoustic emission activity during gear defect diagnosis," NDT \& $E$ International, vol. 36, no. 7, pp. 471-477, 2003.

[12] M. Elforjani and D. Mba, "Accelerated natural fault diagnosis in slow speed bearings with Acoustic Emission," Engineering Fracture Mechanics, vol. 77, no. 1, pp. 112-127, 2010.

[13] K. M. Holford, M. J. Eaton, J. J. Hensman et al., "A new methodology for automating acoustic emission detection of metallic fatigue fractures in highly demanding aerospace environments: an overview," Progress in Aerospace Sciences, vol. 90, pp. 1-11, 2017.

[14] A. Carpinteri, G. Lacidogna, and N. Pugno, "Structural damage diagnosis and life-time assessment by acoustic emission monitoring," Engineering Fracture Mechanics, vol. 74, no. 1-2, pp. 273-289, 2007.

[15] D. Li, C. Hai, and O. Jinping, "Fracture behavior and damage evaluation of polyvinyl alcohol fiber concrete using acoustic emission technique," Materials \& Design, vol. 40, pp. 205-211, 2012.

[16] J. Kaiser, "Erkenntnisse und Folgerungen aus der Messung von Geräuschen bei Zugbeanspruchung von metallischen Werkstoffen," Archiv Für Dassenhüttenwesen, vol. 24, no. 1-2, pp. 43-45, 1953.

[17] R. E. Goodman, "Subaudible noise during compression of rocks," Geological Society of America Bulletin, vol. 74, no. 4, pp. 487-490, 1963. 
[18] V. Rudajev, J. Vilhelm, and T. Lokajiček, "Laboratory studies of acoustic emission prior to uniaxial compressive rock failure," International Journal of Rock Mechanics and Mining Sciences, vol. 37, no. 4, pp. 699-704, 2000.

[19] A. Carpinteri, G. Lacidogna, G. Niccolini, and S. Puzzi, "Critical defect size distributions in concrete structures detected by the acoustic emission technique," Meccanica, vol. 43, no. 3, pp. 349-363, 2008.

[20] X. Fu, Q. Xie, and L. Liang, "Comparison of the Kaiser effect in marble under tensile stresses between the Brazilian and bending tests," Bulletin of Engineering Geology and the Environment, vol. 74, no. 2, pp. 535-543, 2015.

[21] Q. Meng, M. Zhang, L. Han, H. Pu, and T. Nie, "Effects of acoustic emission and energy evolution of rock specimens under the uniaxial cyclic loading and unloading compression," Rock Mechanics and Rock Engineering, vol. 49, no. 10, pp. 3873-3886, 2016.

[22] Y. Liang, Q. Li, Y. Gu, and Q. Zou, "Mechanical and acoustic emission characteristics of rock: effect of loading and unloading confining pressure at the postpeak stage," Journal of Natural Gas Science and Engineering, vol. 44, pp. 54-64, 2017.

[23] T. Qin, H. Sun, H. Liu et al., "Experimental study on mechanical and acoustic emission characteristics of rock samples under different stress paths," Shock and Vibration, vol. 2018, pp. 1-9, 2018.

[24] G. M. Zhao, C. Wang, and D. X. Liang, "Comparative experimental studies of acoustic emission characteristics of sandstone and mudstone under the impacts of cyclic loading and unloading," International Journal of Distributed Sensor Networks, vol. 14, no. 8, pp. 1-10, 2018.

[25] G. Liu, F. K. Xiao, Q. L. Cheng, and T. Qin, "Experimental study on acoustic emission characteristics of dry and saturated basalt columnar joints under uniaxial compression and tensile damage," Shock \& Vibration, vol. 2019, pp. 1-12, 2019.

[26] T. Z. Wang, L. X. Wang, F. Xue, and M. Y. Xue, "Identification of crack development in granite under triaxial compression based on the acoustic emission signal," International Journal of Distributed Sensor Networks, vol. 17, no. 1, pp. 1-15, 2021.

[27] R. Peng, Y. Ju, J. G. Wang, H. Xie, F. Gao, and L. Mao, “Energy dissipation and release during coal failure under conventional triaxial compression," Rock Mechanics and Rock Engineering, vol. 48, no. 2, pp. 509-526, 2015.

[28] P. Wang, J. Xu, X. Fang, and P. Wang, "Energy dissipation and damage evolution analyses for the dynamic compression failure process of red-sandstone after freeze-thaw cycles," Engineering Geology, vol. 221, pp. 104-113, 2017.

[29] H. P. Xie, R. Peng, and Y. Ju, "Energy dissipation of rock deformation and fracture," Chinese Journal of Rock Mechanics and Engineering, vol. 23, no. 21, pp. 3565-3570, 2004.

[30] H. P. Xie, Y. Ju, L. Y. Li, and R. D. Peng, "Energy mechanism of deformation and failure of rock masses," Chinese Journal of Rock Mechanics and Engineering, vol. 27, no. 9, pp. 1729-1740, 2008.

[31] M. Q. You and A. Z. Hua, "Energy analysis of failure process of rock specimens," Chinese Journal of Rock Mechanics and Engineering, vol. 21, no. 6, pp. 778-781, 2002.

[32] F. J. Chen, H. X. Li, and Z. Q. Zhu, "Energy dissipation analysis on unloading confining pressure failure process of rock," Material. Applied Mechanics \& Materials, vol. 259, pp. 398-401, 2013.

[33] A. Carpinteri, M. Corrado, and G. Lacidogna, "Heterogeneous materials in compression: correlations between absorbed, released and acoustic emission energies," Engineering Failure Analysis, vol. 33, pp. 236-250, 2013.

[34] M. Zhang, Q. Meng, and S. Liu, "Energy evolution characteristics and distribution laws of rock materials under triaxial cyclic loading and unloading compression," Advances in Materials Science and Engineering, vol. 2017, pp. 1-16, 2017.

[35] F. Q. Gong, J. Y. Yan, and X. B. Li, "A new criterion of rock burst proneness based on the linear energy storage law and the residual elastic energy index," Chinese Journal of Rock Mechanics and Engineering, vol. 37, no. 9, pp. 1993-2014, 2018.

[36] F. Gong, J. Yan, S. Luo, and X. Li, "Investigation on the linear energy storage and dissipation laws of rock materials under uniaxial compression," Rock Mechanics and Rock Engineering, vol. 52, no. 11, pp. 4237-4255, 2019.

[37] Q. Meng, M. Zhang, L. Han, H. Pu, and Y. Chen, "Acoustic emission characteristics of red sandstone specimens under uniaxial cyclic loading and unloading compression," Rock Mechanics and Rock Engineering, vol. 51, no. 4, pp. 969-988, 2018.

[38] H. Wang, D. Liu, Z. Cui, C. Cheng, and Z. Jian, "Investigation of the fracture modes of red sandstone using XFEM and acoustic emissions," Theoretical and Applied Fracture Mechanics, vol. 85, pp. 283-293, 2016.

[39] P. Rodríguez and T. B. Celestino, "Application of acoustic emission monitoring and signal analysis to the qualitative and quantitative characterization of the fracturing process in rocks," Engineering Fracture Mechanics, vol. 210, pp. 54-69, 2019.

[40] Y. Jin, Z. Qi, M. Chen, G. Zhang, and G. Xu, “Time-sensitivity of the Kaiser effect of acoustic emission in limestone and its application to measurements of in-situ stress," Petroleum Science, vol. 6, no. 2, pp. 176-180, 2009.

[41] A. D. Papargyris, R. G. Cooke, S. A. Papargyri, and A. I. Botis, "The acoustic behaviour of bricks in relation to their mechanical behaviour," Construction and Building Materials, vol. 15, no. 7, pp. 361-369, 2001.

[42] A. Lavrov, "The Kaiser effect in rocks: principles and stress estimation techniques," International Journal of Rock Mechanics and Mining Sciences, vol. 40, no. 2, pp. 151-171, 2003.

[43] A. Carpinteri, G. Lacidogna, M. Corrado, and E. Di Battista, "Cracking and crackling in concrete-like materials: a dynamic energy balance," Engineering Fracture Mechanics, vol. 155, pp. 130-144, 2016.

[44] A. Carpinteri and F. Accornero, "Multiple snap-back instabilities in progressive microcracking coalescence," Engineering Fracture Mechanics, vol. 187, pp. 272-281, 2018.

[45] G. Lacidogna, F. Accornero, and A. Carpinteri, "Influence of snap-back instabilities on Acoustic Emission damage monitoring," Engineering Fracture Mechanics, vol. 210, pp. 3-12, 2019.

[46] H. P. Xie, Y. Ju, and L. Y. Li, "Criteria for strength and structural failure of rocks based on energy dissipation and energy release principles," Chinese Journal of Rock Mechanics and Engineering, vol. 24, no. 17, pp. 3003-3010, 2005.

[47] H. Xie, L. Li, R. Peng, and Y. Ju, "Energy analysis and criteria for structural failure of rocks," Journal of Rock Mechanics and Geotechnical Engineering, vol. 1, no. 1, pp. 11-20, 2009. 